\section{Geologic occurrence and recent eruptive materials of the Lautaro Volcano, Chilean Patagonia}

\section{Akihisa Motoki *, Yuji Orihashi **, Jose Antonio Naranjo ****, Daiji Hirata ****;, Takahiro Hosono *****;, Felipe Dias Cario *******, Ryo Anma ******}

Received Deceber 20, 2002 Accepted March 27, 2003

* Rio de Janeiro State University (DMPIUERJ), Brazil. Motoki@uerj.br

** $\quad$ Earthquake Research Institute (ERI), University of Tokyo. Japan

*** Servicio Nacional de Geología y Minería, Chile.

**** Kanagawa Prefecture Museum. Japan

***** Tsukuba University. Japan

****** Fluminense Federal University (LAGEMAR/UFF), Brazil.

The Lautaro Volcano, Chilean Patagonia, is situated at $49^{\circ} 01.4^{\prime} \mathrm{S}, 73^{\circ} 32.5^{\prime}$ $\mathrm{W}$, being the closest volcano to the Chile Triple Junction, in which on-going subduction of active ridge takes place. The volcanoes of the Austral Volcanic Zone are characterised by adakitic composition (Stern and Killian, 1996), and their magma origin is attributed to slab-melting. Such typical ridge subduction volcanism can clarify juvenile continental crust formation process, as a modern analogue of Archaean magmatism.

The access to the Lautaro Volcano, 3,607 $\mathrm{m}$ above the sea level, is extremely difficult because of accidental morphology and unfavourable climate conditions. The volcano edifice stands out from the glacial plateau of 2,400 $\mathrm{m}$ high, so-called South Ice Field, therefore, no research group had got rock samples in enough amount and variety. On February 28, 2002, with help of helicopter, the authors' research group accomplished a successful sampling of eruptive materials of this volcano from deposits of the Lautaro Glacier, first target, and the O'Higgins Glacier, second target.

\section{References}

Stern, C. and Killian R., 1996, Role of the sbuducted slab, mantle wedge and continental crust in the generation of adakite from the Andea Austral Volcanic Zone. Contrib. Mineral. Petrol., 123, 263-281.
A

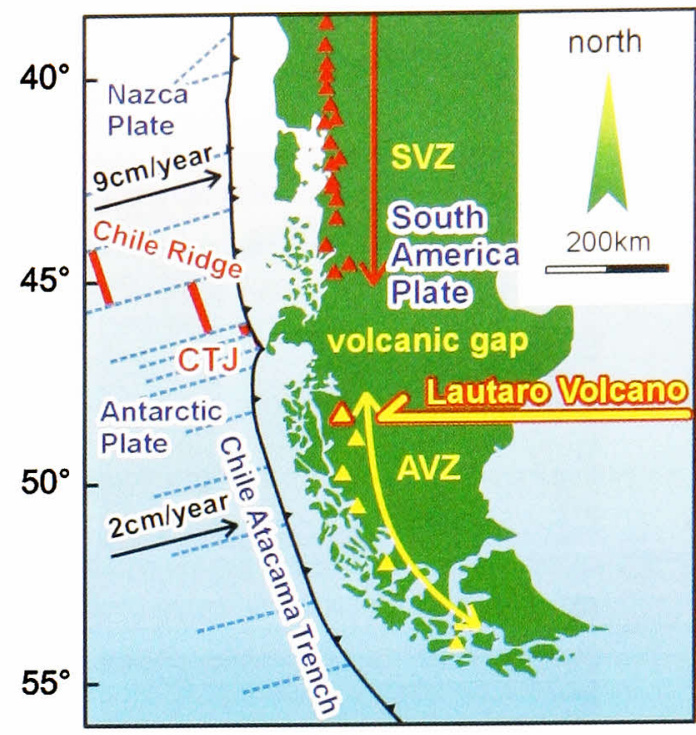

\section{B}

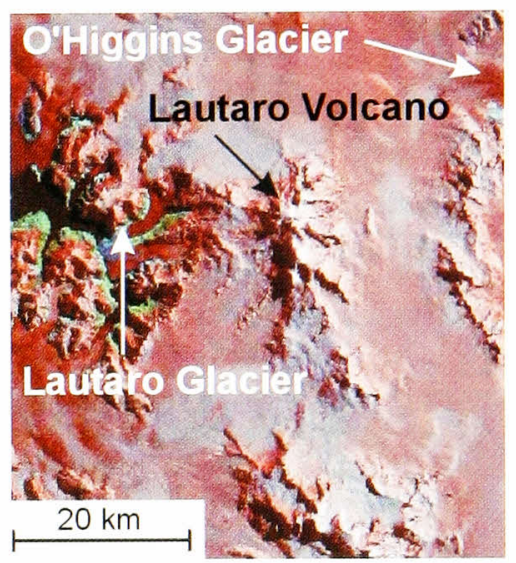

Fig. 1. Locality map (A) and satellite photograph (B) of the Lautaro Volcano and the Austral Volcanic Zone, Patagonia, indicating the Lautaro Glacier, first target, and the O'Higgins Glacier, second target.

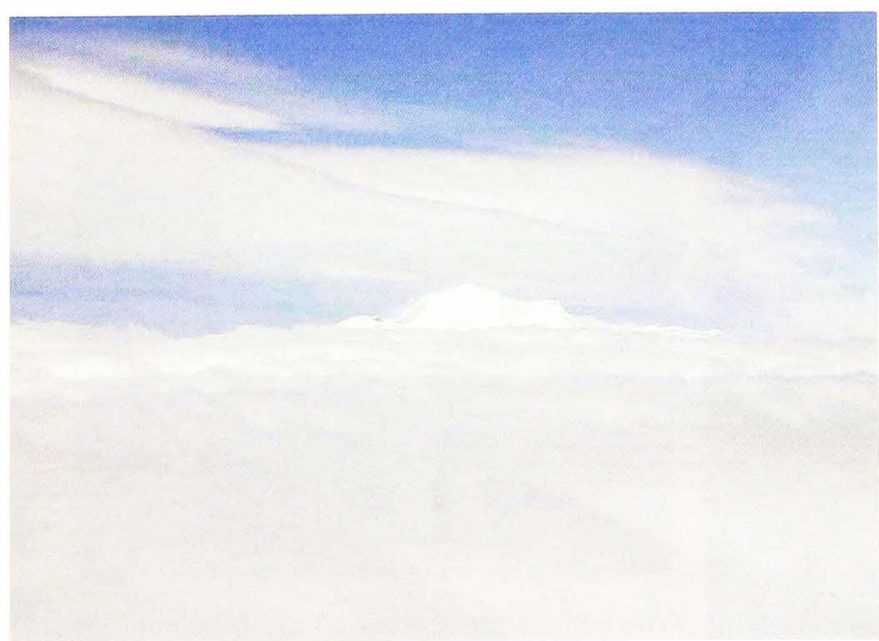

Fig. 2. The Lautaro Volcano seen from the helicopter.

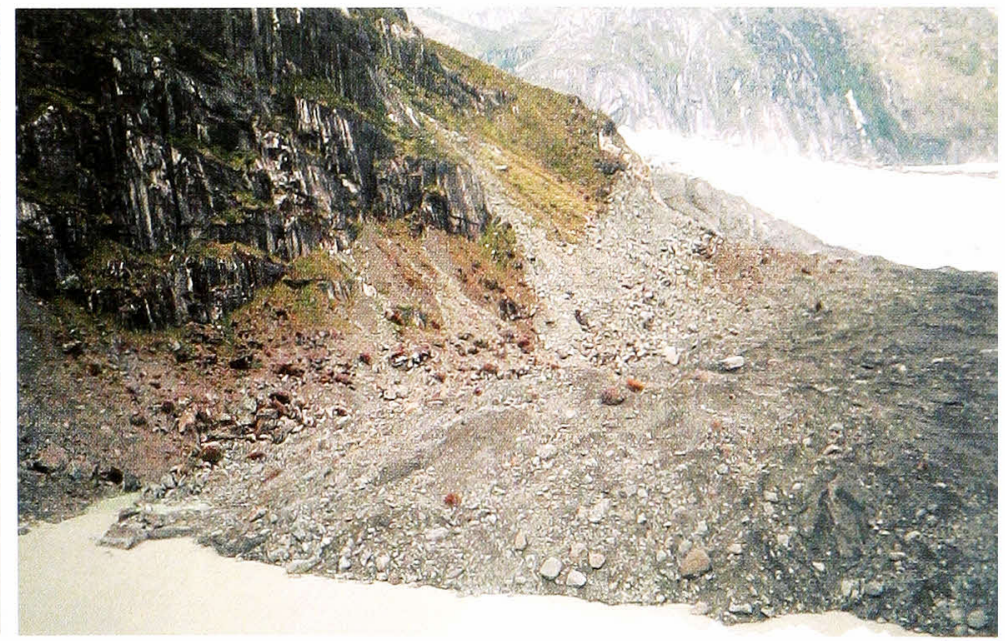

Fig. 3. Recessional terminal moraine of the Lautaro Glacier, the first target. 
A
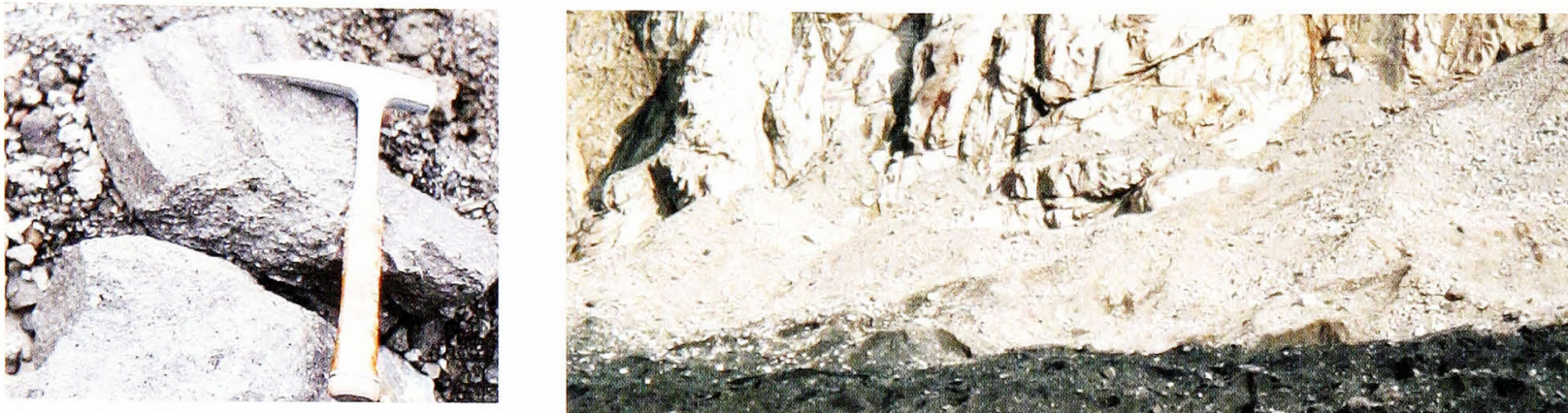

B
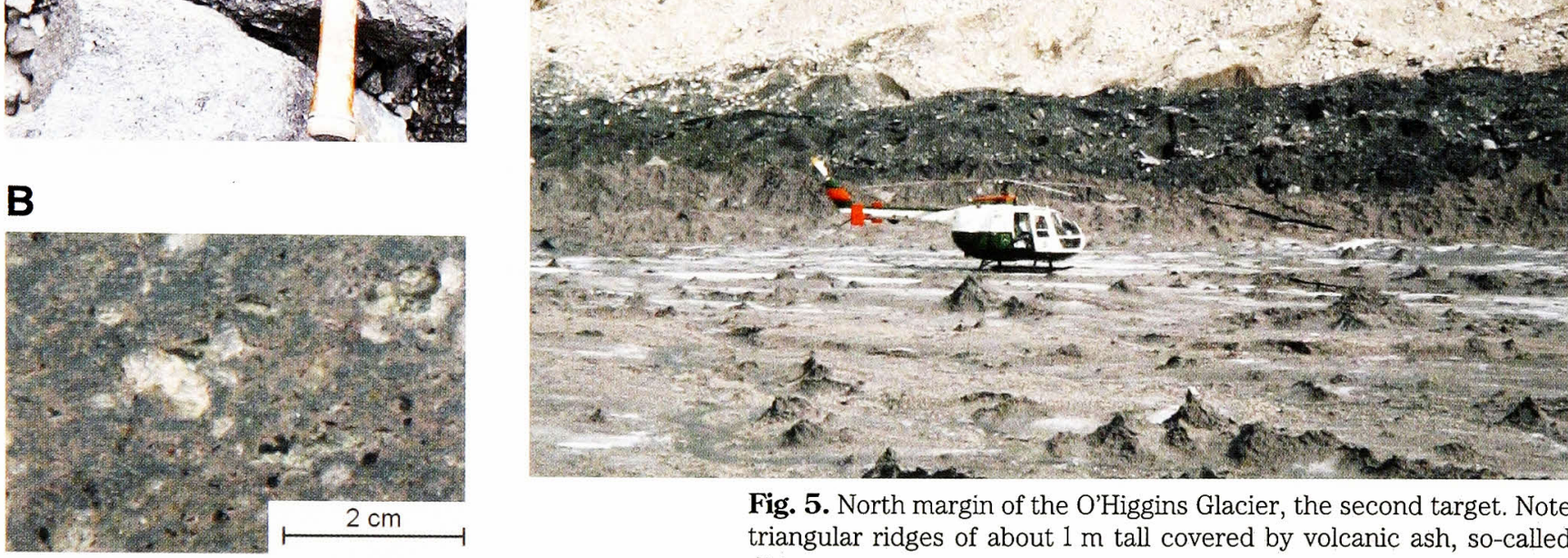

Fig. 5. North margin of the O'Higgins Glacier, the second target. Note triangular ridges of about $1 \mathrm{~m}$ tall covered by volcanic ash, so-called dirt cones.

Fig. 4. Occurrence of prismatically jointing blocks suggesting lava dome collapse (A) and its constituent dacitic rock (B), found at the first target.

A

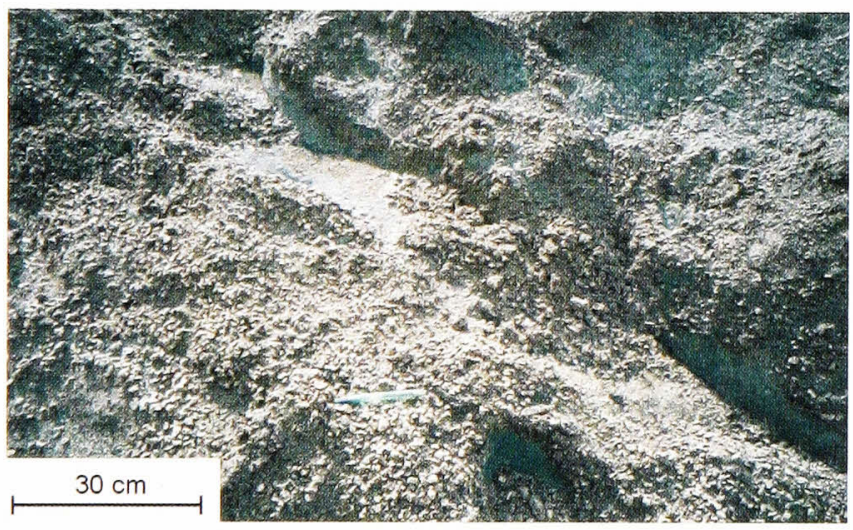

B

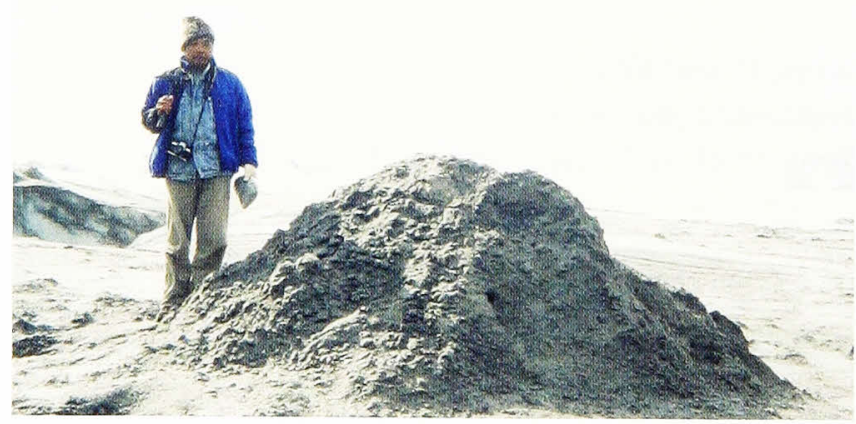

Fig. 6. Pumice on the ice surface (A) and ash-size tephra on a dirt cone (B), found on the O'Higgins Glacier, originated from a recent eruption of the Lautaro Volcano.

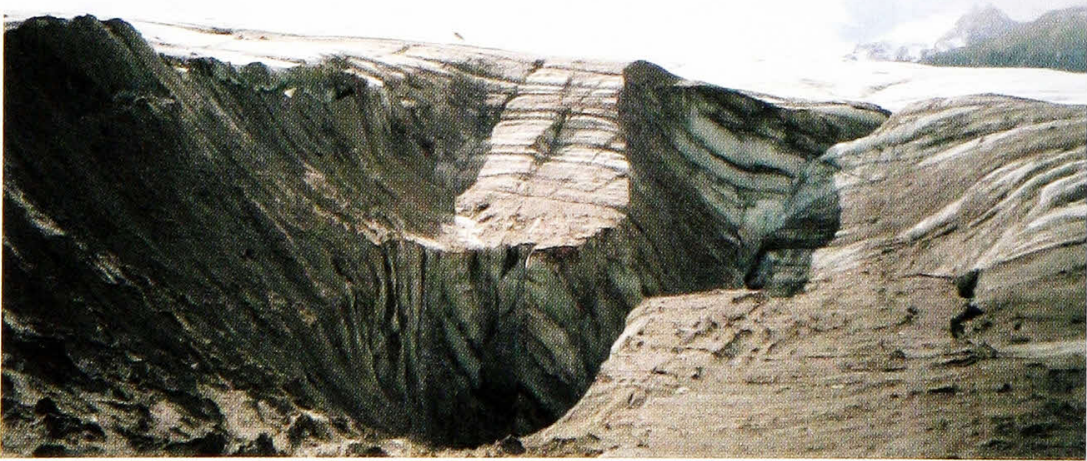

Fig. 7. Ash layers present in the O'Higgins Glacier, suggesting existence of multiple recent eruptions of the Lautaro Volcano.

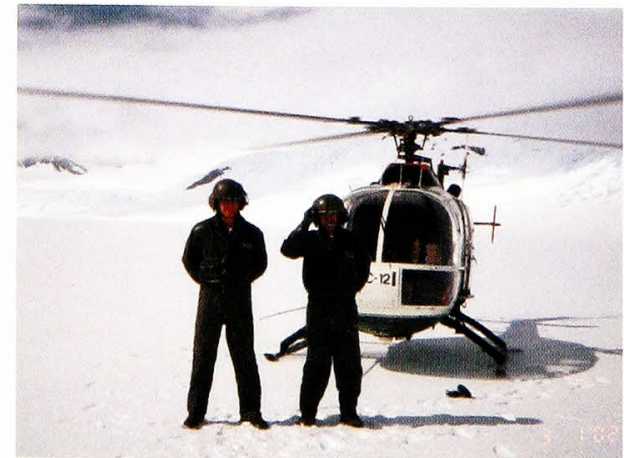

The authors are grateful to the helicopter pilots, Lieutenant Cristian Cofre and Lieutenant Jorge Carrasco of the Chilean Police Department (Carabineros de Chile). 